\title{
Behavioral Profiles and Attitude toward Condom Use among College Students in Southwest Ethiopia
}

\author{
Tewodros Yosef $(\mathbb{D}$ and Tadesse Nigussie $\mathbb{D}$ \\ Department of Public Health, College of Medicine and Health Sciences, Mizan-Tepi University, Mizan Teferi, Ethiopia \\ Correspondence should be addressed to Tewodros Yosef; tewodrosyosef47@mtu.edu.et
}

Received 3 April 2020; Revised 28 July 2020; Accepted 3 September 2020; Published 24 September 2020

Academic Editor: Kumud K. Kafle

Copyright ( 2020 Tewodros Yosef and Tadesse Nigussie. This is an open access article distributed under the Creative Commons Attribution License, which permits unrestricted use, distribution, and reproduction in any medium, provided the original work is properly cited.

\begin{abstract}
Background. Unsafe sexual behavior among adolescents still represents a public health challenge. To have safe sex, effective condom utilization is needed. Condom use remains relatively low among adolescents in sub-Saharan Africa. Even though adolescents have good knowledge about condom use, they are still engaged in risky sexual behavior. Objective. To assess condom use and attitude toward condom use among college students in southwest Ethiopia. Methods. A cross-sectional study was conducted among 453 students at Mizan-Aman Polytechnic College in southwest Ethiopia. Data were collected using a structured self-administered questionnaire. The collected data were entered using EpiData version 4.2.0.0 and analyzed using SPSS version 20 statistical software. Binary logistic regression was computed. Independent variables with a $p$ value of less than 0.05 in the multivariable logistic regression model were considered significant. Results. Of the 453, 180 were sexually active. Among those sexually active, $119(66.1 \%)$ used condoms in their last sexual intercourse. The proportion of positive attitude toward condom use was 53.4\%, and the mean attitude score for condom use was 28.6 ( $\pm 9.99 \mathrm{SD})$ ranging from 10 to 50 . The study also found that being male $(\mathrm{AOR}=1.77,95 \% \mathrm{CI}[1.19-2.65])$, rural resident $(\mathrm{AOR}=2.20,95 \% \mathrm{CI}[1.47-3.30])$, ever had sex $(\mathrm{AOR}=1.87,95 \% \mathrm{CI}[1.23-$ $2.85]$ ), and knowledge of STIs ( $\mathrm{AOR}=1.66,95 \% \mathrm{CI}[1.10-2.51]$ ) were factors associated with a positive attitude toward condom use. Conclusion. The proportion of positive attitude toward condom use among college students in Ethiopia was low. The study also found that being male, rural resident, ever had sex, and knowledge of STIs were factors associated with a positive attitude toward condom use. Therefore, strengthening information, education, and communication (IEC) on condom self-efficacy; providing condoms on campuses; and imparting education about sexually transmitted infections for young adults are central for improving condom use and attitudes toward condom use. Besides, inculcating sexual and reproductive health in the educational curriculum plays paramount importance.
\end{abstract}

\section{Introduction}

Sexually transmitted diseases (STDs) are current public health concerns [1] and are considered a major global cause of acute illness, infertility, long-term disability, and death, with serious medical and psychological consequences for millions of men and women. Its prevalence is high in developing countries, resulting in substantial losses of productivity among individuals and communities, where the majority of the population is less than 40 years of age $[2,3]$. STDs are associated with increased transmission of human immunodeficiency virus/acquired immune deficiency syndrome (HIV/AIDS) and poor reproductive and sexual health [4].
Globally, a condom is considered an important method for the prevention of sexually transmitted infections, especially HIV/AIDS, and a means to prevent unwanted pregnancy [5-8]. Condom use among young adults has been increasing over the past two decades. However, its magnitude varies from more than $80 \%$ in some Latin American and European countries to less than $30 \%$ in some African countries [9]. STIs are mostly transmitted through sexual intercourse through unsafe sex [10]. Unsafe sexual behavior among young adults still represents a public health challenge [11-13]. To have safe sex, effective condom utilization is needed [14]. For condoms to be effective, they have to be consistently and continuously used. Despite the various promotion methods, 
condom use remains relatively low among adolescents in subSaharan Africa [15-17].

Different studies conducted globally regarding the prevalence of condom use reported that $53 \%$ and $50.3 \%$ in Tanzania $[12,18], 24 \%$ in the Democratic Republic of Congo [19], $38.6 \%$ in Nigeria [6], 68.3\% in Ethiopia [20], 16.6\% in Kenya [21], 12\% in Iraq [5], and 51\% in Spain [22] of the participants used condoms during their last sexual intercourse.

Having good knowledge about condoms does not guarantee its utilization. Young adults with good knowledge about condoms are still engaged in risky sexual behavior (unsafe sex) [15]. Condom use for safe sex is mainly influenced by attitudes toward condom use [22]. Studies conducted elsewhere regarding attitude toward condom use reported that $52 \%$ in the Democratic Republic of Congo [19] and $68.8 \%$ in Iraq [5] had positive attitudes toward condom use. The factors associated with attitude toward condom use are diverse and may include age, sex, residence, marital status, religion, educational status, and knowledge of STIs [15, 16, 18, 23-26].

A dramatic increase in human immunodeficiency virus (HIV) infection among young people has become alarming in Ethiopia [27]. Even though premarital sex relationships are widely discouraged in Ethiopia, young people in colleges become highly engaged in risky sexual behaviors [28, 29] due to a sense of independence from restrictions and parental impact. Studies were done previously regarding the magnitude of condom use [20] and the descriptive nature of attitude toward condom use [30] in Ethiopia. But no study has clearly shown the attitude toward condom use and its associated factors in these populations. Therefore, this study is aimed at assessing condom use and attitude toward condom use among college students in southwest Ethiopia.

\section{Materials and Methods}

2.1. Study Design, Setting, and Period. A cross-sectional study was conducted at Mizan-Aman Polytechnic College (MAPtC) students from April 01 to 30, 2018. MAPtC is found at $585 \mathrm{~km}$ southwest of Addis Ababa, the capital city of Ethiopia. The college was established in 2005. The college teaches students in ten departments, with five/four levels for each department. The departments were garment and textile, automotive, road construction, water and sanitation, information communication technology, building electrical installation, electrotechnology, masonry construction, general metal fabrication, and surveying technology. The college had a total of 1810 students (920 male and 890 female) during the study period. All students were not in dormitories (live outside of the college) [31].

2.2. Populations. The source population includes all regular college students, who attended their class during the study period. The study population includes randomly selected students who studied during the study period.

2.3. Sample Size Determination and Sampling Method. The sample size was determined using a single population proportion formula using the following assumptions: the expected proportion of positive attitude toward condom use was $83.6 \%$ [30], 5\% precision level, 95\% confidence interval,
$10 \%$ for nonresponse compensation, and a design effect of 2. The final computed sample size was 464. A stratified random sampling technique was used to select 464 regular students. In Mizan-Aman Polytechnic College, there were ten departments with five/four levels for each department. The departments were stratified based on levels (levels I-V). For each level, the sample size is proportionally allocated. The potential participants were selected using systematic random sampling.

2.4. Data Collection Instrument and Procedures. The data were collected through structured self-administered and pretested questionnaire. The questionnaire is composed of sociodemographic characteristics, attitude questions regarding condom use, and behavioral profiles. The questionnaire was developed by reviewing relevant literatures in English, then translated into the local language (Amharic), and back-translated into English to check the consistency by an independent translator. The training was given to data collectors and supervisors concerning the objective and process of data collection to discuss the presence of an ambiguous question in the questionnaire.

2.5. Study Variables. The dependent variable was attitude toward condom use. The independent variables were age, sex, residence, marital status, academic level, ever had sex, number of sexual partners, and knowledge about STIs.

2.6. Operational Definitions. Ever had sex (sexually active) was defined as a study subject who had at least one sexual intercourse before the study. Multiple sexual partners was defined as having more than one sexual partner. Practice condom use was defined as using a condom by respondents in their last sexual intercourse. Positive attitude toward condom use was defined as when respondents scored the mean and above the value of attitude toward condom-related questions, otherwise negative attitude toward condom use.

2.7. Data Processing and Analysis. The completeness and consistency of the data were checked, coded, and entered into EpiData 4.2.0.0. The data were exported to SPSS version 20 statistical software for further analysis. Descriptive and summary statistics were carried out. The results are presented in tables and numerical summary measures such as mean and standard deviation (SD). Bivariate and multivariable logistic regression analyses were used to identify variables associated with attitude toward condom use. Independent variables with a $p$ value of less than 0.25 in bivariate logistic regression were included in the multivariable logistic regression model. Finally, variables with a $p$ value $<0.05$ in the multivariable logistic regression model were considered significantly associated with the dependent variable. The Hosmer-Lemeshow goodness-of-fit test indicated $(p=0.740)$ that the model was good enough to fit the data well.

\section{Results}

3.1. Sociodemographic Characteristics. Of the 464, 453 students filled the questionnaire with a response rate of $97.6 \%$. The mean age of respondents was 19.95 ( \pm 2 SD) ranging 
from 18 to 30 years. The majority of the respondents were male (53.6\%), single (88.1\%), and orthodox Christian followers $(54.7 \%)$. More than half of the study participants were from urban residence $(57.6 \%)$, and $52.1 \%$ were in the age group of 20 years and above (Table 1 ).

3.2. Behavioral Profiles. Almost one-tenth (10.4\%) of the respondents were cigarette smokers. One hundred seven $(23.6 \%)$ and $172(38 \%)$ of the respondents were alcohol drinkers and watching pornography at least once in their lifetime, respectively. Of the 180 sexually active, 119 (66.1\%) and $82(45.6 \%)$ used condoms in their last sexual intercourse and had multiple sexual partners, respectively (Table 2).

3.3. Attitude Score of Condom Use. The mean attitude score of respondents was $28.6( \pm 9.99 \mathrm{SD})$ with a range of 10 to 50 . Two hundred forty-two (53.4\%) respondents had a positive attitude toward condom use. Two hundred twenty-three (49.2\%) of the participants agreed with "condoms as an effective method of preventing pregnancy." One hundred ninetyone $(42.2 \%)$ of the study subjects agreed that "condom reduces sexual pleasure." The majority of 212 (46.8\%) study subjects agreed with "feeling protected while using a condom." One hundred fifty-nine (35.1\%) of the study subjects agreed that "condoms are too expensive to buy." Ninety-six (21.2\%) and 133 (29.9\%) respondents disagreed with "condoms are suitable for casual sex" and "condoms are suitable for steady relationships," respectively (Table 3).

3.4. Factors Associated with Attitude toward Condom Use. The association between the independent variables and the dependent variable (attitude toward condom use) was tested using binary logistic regression analysis. Independent variables found statistically significant at $p<0.25$ in the bivariate analysis were included in the multivariable binary logistic regression model. Finally, being a male, rural resident, ever had sex, and knowledge of STIs were significantly associated with a positive attitude toward condom use (Table 4).

\section{Discussion}

Young adults with good knowledge about condoms are still engaged in unsafe sexual practice [15]. To have safe sex, effective condom utilization is needed [14]. Condom use for safe sex is mainly influenced by attitudes toward condom use [22]. Based on the above scenario, we aimed to assess condom use and attitude toward condom use among college students in southwest Ethiopia. The proportion of positive attitude toward condom use was 53.4\% (48.8\%-58\%). This study was in line with $52 \%$ in the Democratic Republic of Congo [19]. It was lower than $68.8 \%$ in Iraq [5].

The proportion of condom use was $66.1 \%$ (61.7\%-70.5\%). This study was in line with $68.3 \%$ in Ethiopia [20]. It was higher than $53 \%$ and $50.3 \%$ in Tanzania $[12,18], 24 \%$ in the Democratic Republic of Congo [19], 38.6\% in Nigeria [6], $16.6 \%$ in Kenya [21], 12\% in Iraq [5], and 51\% in Spain [22]. The variation observed compared to other studies could be due to the differences in sample size, the operational definition used, and methodology in general. In addition, socioeconomic, behavioral/lifestyle, cultural, religious, and educational
TABLE 1: Sociodemographic characteristics of the respondents at MAPtC in southwest Ethiopia.

\begin{tabular}{lccc}
\hline Variables & Categories & Frequency & Percent \\
\hline \multirow{2}{*}{ Sex } & Male & 243 & 53.6 \\
\multirow{2}{*}{ Age } & Female & 210 & 46.4 \\
& $<20$ years & 217 & 47.9 \\
Religion & $\geq 20$ years & 236 & 52.1 \\
& Orthodox & 248 & 54.7 \\
& Protestant & 144 & 31.8 \\
Marital status & Muslim & 61 & 13.5 \\
& Single & 399 & 88.1 \\
\multirow{3}{*}{ Residence } & Married & 46 & 10.2 \\
& Divorced & 8 & 1.7 \\
& Rural & 192 & 42.4 \\
& Urban & 261 & 57.6 \\
Academic level & First year & 51 & 11.3 \\
& Second year & 98 & 21.6 \\
& Third year & 180 & 39.7 \\
& Fourth year & 124 & 27.4 \\
\hline
\end{tabular}

TABLE 2: Behavioral profiles of the respondents at MAPtC in southwest Ethiopia.

\begin{tabular}{lccc}
\hline Variables & Categories & Frequency & Percent \\
\hline Cigarette smoking $(n=453)$ & Yes & 47 & 10.4 \\
& No & 406 & 89.6 \\
Drinking alcohol $(n=453)$ & Yes & 107 & 23.6 \\
& No & 346 & 76.4 \\
Watching pornography $(453)$ & Yes & 172 & 38 \\
& No & 281 & 62 \\
Sexually active (ever had sex) & Yes & 180 & 39.7 \\
& No & 273 & 61.3 \\
Condom use $(n=180)$ & Yes & 119 & 66.1 \\
& No & 61 & 33.9 \\
Number of sexual partners & $<2$ & 98 & 54.4 \\
$(n=180)$ & $\geq 2$ & 82 & 45.6 \\
\hline
\end{tabular}

profiles of the study population may create a significant variation.

Sex was statistically associated with an attitude toward condom use in this study. Being male was associated with a positive attitude toward condom use. Male respondents were associated with 1.8 times increased odds of having a positive attitude toward condom use than female respondents. This could be due to the greater utilization of condoms by males (77.3\%). Repeated condom use may create adaptation and a positive attitude to condom use. This study was consistent with studies conducted in Kenya and Tanzania [15, 18]. Besides, the association is better supported by the high prevalence of herpes simplex virus observed among females resulting from less attitude and practice toward condom use [32]. But a study conducted in Croatia suggests that 
TABLE 3: Attitude score of condom use among respondents at MAPtC in southwest Ethiopia.

\begin{tabular}{|c|c|c|c|c|c|}
\hline Questions & Strongly disagree & Disagree & Not sure & Agree & Strongly agree \\
\hline $\begin{array}{l}\text { Condoms are an effective method of } \\
\text { preventing pregnancy }\end{array}$ & $68(15 \%)$ & $37(8.2 \%)$ & $125(27.6 \%)$ & $108(23.8 \%)$ & $115(25.4 \%)$ \\
\hline $\begin{array}{l}\text { It is embarrassing for me to ask my partner } \\
\text { to use a condom }\end{array}$ & $87(19.2 \%)$ & $57(12.6 \%)$ & $111(24.5 \%)$ & $98(21.6 \%)$ & $100(22.1 \%)$ \\
\hline Condoms are suitable for casual sex & $66(14.6 \%)$ & $30(6.6 \%)$ & $120(26.5 \%)$ & $105(23.2 \%)$ & $132(29.1 \%)$ \\
\hline Condoms are suitable for steady relationships & $73(16.7 \%)$ & $60(13.2 \%)$ & $138(30.5 \%)$ & $85(18.8 \%)$ & $97(21.4 \%)$ \\
\hline $\begin{array}{l}\text { It would be too embarrassing for me to buy } \\
\text { or obtain condoms }\end{array}$ & $99(21.9 \%)$ & $52(11.5 \%)$ & $119(26.3 \%)$ & $70(15.5 \%)$ & $113(24.9 \%)$ \\
\hline Condoms reduce sexual pleasure & $76(16.8 \%)$ & $31(6.8 \%)$ & $155(34.2 \%)$ & $104(23 \%)$ & $87(19.2 \%)$ \\
\hline I feel protected while using a condom & $82(18.1 \%)$ & $33(7.3 \%)$ & $126(27.8 \%)$ & $110(24.3 \%)$ & $102(22.5 \%)$ \\
\hline Condoms are too expensive to buy & $101(22.3 \%)$ & $60(13.2 \%)$ & $133(29.4 \%)$ & $83(18.3 \%)$ & $76(16.8 \%)$ \\
\hline Condoms affect the mood in a negative way & $102(22.5 \%)$ & $44(9.7 \%)$ & $160(35.3 \%)$ & $91(20.1 \%)$ & $56(12.4 \%)$ \\
\hline $\begin{array}{l}\text { It is hard to tell my partner to use a condom } \\
\text { if he/she does not want to use it }\end{array}$ & $103(22.7 \%)$ & $69(15.2 \%)$ & $121(26.7 \%)$ & $89(19.6 \%)$ & $71(15.7 \%)$ \\
\hline
\end{tabular}

TABLE 4: Factors associated with positive attitudes toward condom use of the respondents at MAPtC in southwest Ethiopia.

\begin{tabular}{|c|c|c|c|c|c|}
\hline \multirow[t]{2}{*}{ Variables } & \multirow[t]{2}{*}{ Categories } & \multicolumn{2}{|c|}{ Attitude toward condom use } & \multirow{2}{*}{ COR $(95 \%$ CI $)$} & \multirow{2}{*}{ AOR (95\% CI) } \\
\hline & & Negative & Positive & & \\
\hline \multirow{2}{*}{ Age group } & $<20$ years & 110 & 107 & 1 & 1 \\
\hline & $\geq 20$ years & 101 & 135 & $1.37(0.95-1.99)$ & $1.06(0.70-1.59)$ \\
\hline \multirow{2}{*}{ Sex } & Male & 92 & 151 & $2.15(1.47-3.13)$ & $1.77(1.19-2.65)^{* *}$ \\
\hline & Female & 119 & 91 & 1 & 1 \\
\hline \multirow{2}{*}{ Residence } & Rural & 69 & 123 & $2.13(1.45-3.12)$ & $2.20(1.47-3.30)^{* *}$ \\
\hline & Urban & 142 & 119 & 1 & 1 \\
\hline \multirow{3}{*}{ Marital status } & Single & 180 & 190 & 1 & 1 \\
\hline & Married & 16 & 33 & $2.38(1.22-4.65)$ & $1.70(0.82-3.52)$ \\
\hline & Divorced & 15 & 19 & $0.56(0.13-2.38)$ & $0.40(0.09-1.73)$ \\
\hline \multirow{2}{*}{ Ever had sex } & Yes & 63 & 117 & $2.20(1.49-3.24)$ & $1.87(1.23-2.85)^{* *}$ \\
\hline & No & 148 & 125 & 1 & 1 \\
\hline \multirow{2}{*}{ Knowledge of STIs } & Good & 147 & 129 & $2.01(1.37-2.96)$ & $1.66(1.10-2.51)^{*}$ \\
\hline & Poor & 64 & 113 & 1 & 1 \\
\hline
\end{tabular}

$\mathrm{CI}=$ confidence interval; $\mathrm{COR}=$ crude odds ratio; $\mathrm{AOR}=$ adjusted odds ratio. ${ }^{*}$ Significant at a $p$ value $<0.05 .{ }^{* *}$ Significant at a $p$ value $<0.01$.

women expressed a more positive attitude toward condom use than men [23].

Respondents who were from rural areas were associated with 2.2 times increased odds of having a positive attitude toward condom use than those from urban areas. Being from rural areas was associated with a positive attitude toward condom use. This finding was consistent with a study in Ethiopia [24].

In this study, ever had sex was statistically associated with a positive attitude toward condom use. Respondents who ever had sex were 1.9 times more likely to have a positive attitude toward condom use than those who did not. This finding was consistent with a study $[16,25]$. This could be due to previous exposure to condoms which helps them develop a positive attitude toward condom use.

Respondents who had good knowledge of STIs were 1.7 times more likely to have a positive attitude toward condom use than poor knowledge of STIs. Good knowledge about STIs was associated with a positive attitude toward condom use. This finding was consistent with studies conducted in Kenya, Croatia, and Thailand $[15,23,26]$. But another study revealed that knowledge of sexually transmitted diseases, including HIV/AIDS and condoms, was not associated with more positive attitudes toward condom use or intention to use condoms with either steady or casual partners [16].

\section{Conclusion}

The proportion of positive attitude toward condom use among college students in Ethiopia was low. The study also found that being male, rural resident, ever had sex, and knowledge of STIs were factors associated with a positive attitude toward condom use. Therefore, strengthening information, education, and communication (IEC) on condom 
self-efficacy; providing condoms on campuses; and imparting education about sexually transmitted infections for young adults are central for improving condom use and attitudes toward condom use. Besides, inculcating sexual and reproductive health in the educational curriculum plays paramount importance.

\section{Abbreviations}

$\begin{array}{ll}\text { AOR: } & \text { Adjusted odds ratio } \\ \text { CI: } & \text { Confidence interval } \\ \text { COR: } & \text { Crude odds ratio }\end{array}$

MAPtC: Mizan-Aman Polytechnic College

SPSS: $\quad$ Statistical Package for the Social Sciences

SD: $\quad$ Standard deviation

STIs: Sexually transmitted infections.

\section{Data Availability}

The dataset is handled by the corresponding author and can be provided upon request.

\section{Additional Points}

Limitations. The nature of the study (cross-sectional study) may not show a cause-and-effect relationship. Besides, the possibility of social desirability bias may be considered a limitation to this study, since some instructors of the college served as a facilitator as well as a supervisor for the data collection process; the response of the respondents may resulted in either overestimate (respond more on good behavior) and underestimate (respond less on bad/undesirable behavior) report. This may shadow their response for interview questions.

\section{Ethical Approval}

Ethical approval was obtained from the Mizan-Tepi University-Institutional Review Board (MTU-IRB). Ethical approval was given on 25/02/2018 and has a number of MTUIRB/089/2018.

\section{Consent}

The study participants were informed about the purpose of the study, their right to deny participation, anonymity, and confidentiality of the information. The confidentiality of the response was maintained. Personal privacy and cultural norms were respected properly. Written informed consent was obtained from participants who participated in the study.

\section{Conflicts of Interest}

The authors declare no conflicts of interest.

\section{Authors' Contributions}

All authors were involved in the conception, design, acquisition of data, analysis, and interpretation of the results. Tewodros Yosef drafted the manuscript, and then all authors approved it for publication.

\section{Acknowledgments}

First, we would like to thank all study participants for their participation. Second, our thank goes to the academic and administrative staff at Mizan-Aman Polytechnic College who gave us full collaboration during the study period.

\section{References}

[1] M. W. Eysenck, M. Reis, L. Ramiro, M. G. Matos, and J. A. Diniz, "Nationwide survey of contraceptive and sexually transmitted infection knowledge, attitudes and skills of university students in Portugal," International Journal of Clinical and Health Psychology, vol. 13, no. 2, pp. 127-137, 2013.

[2] N. D. Megersa, S. M. Ahmed, B. T. Gutema, G. S. Teshome, Z. A. Melketsedik, and E. Z. Tariku, "Knowledge, attitude and preventive practices towards sexually transmitted infection among preparatory school students of Arsi Negelle," Journal of AIDS and Clinical Research, vol. 8, no. 12, pp. 8-13, 2017.

[3] T. S. Mengistu, A. T. Melku, N. D. Bedada, and B. T. Eticha, "Risks for STIs/HIV infection among Madawalabu University students, Southeast Ethiopia : a cross sectional study," Reprod Health, vol. 10, no. 1, p. 38, 2013.

[4] S. C. Francis, T. N. Mthiyane, K. Baisley et al., "Prevalence of sexually transmitted infections among young people in South Africa : a nested survey in a health and demographic surveillance site," PLOS Medicine, vol. 15, no. 2, p. e1002512, 2018.

[5] A. S. Ismael and J. M. Sabir Zangana, "Knowledge, attitudes and practice of condom use among males aged (15-49) years in Erbil Governorate," Global Journal of Health Science, vol. 4, no. 4, pp. 27-36, 2012.

[6] A. I. Ajayi, K. O. Ismail, and W. Akpan, "Factors associated with consistent condom use: a cross-sectional survey of two Nigerian universities," BMC Public Health, vol. 19, no. 1, pp. 1207-1211, 2019.

[7] M. A. Abdulai, F. Baiden, S. Afari-Asiedu et al., "The risk of sexually transmitted infection and its influence on condom use among pregnant women in the Kintampo North Municipality of Ghana," Journal of Sexually Transmitted Diseases, vol. 2017, no. 1, Article ID 8642685, p. 12, 2017.

[8] M. Miskulin, I. Miskulin, D. Puntaric, A. Mujkic, and N. B. Josip Milas, "The characteristics of sexual behavior and extent of condom usage among sexually active Croatians from Eastern Croatia," Journal of the Turkish German Gynecological Association, vol. 10, pp. 142-147, 2010.

[9] UNAIDS, "Condoms: the prevention of HIV, other sexually transmitted infections and unintended pregnancies," Meet Report, 2016.

[10] World Health Organization, "Global strategy for the prevention and control of sexually transmitted infections," Breaking the chain of transmission, p. 2007, 2006-2015.

[11] A. Onoja, A. Bala, and M. Umar, "Awareness level of safe sex among students of the University of Maiduguri, Borno State, Nigeria," African Journal of Nursing and Midwifery, vol. 5, no. 3, pp. 704-712, 2017.

[12] A. Kalolo and S. M. Kibusi, "The influence of perceived behaviour control, attitude and empowerment on reported condom use and intention to use condoms among adolescents in rural Tanzania," Reproductive Health, vol. 12, no. 1, 2015.

[13] M. Miskulin, D. Puntaric, I. Miskulin, B. Atalic, and T. Dijanic, "Sexual behaviour of Croatian blood donors as a threat to the 
health of blood recipients," Blood Transfusion, vol. 9, no. 4, pp. 407-412, 2011.

[14] L. M. Adams and B. H. Balderson, "HIV providers' likelihood to prescribe pre-exposure prophylaxis (PrEP) for HIV prevention differs by patient type: a short report," AIDS Care, vol. 28, no. 9, pp. 1154-1158, 2016.

[15] W. J. Esther, Knowledge, attitude and practice of condom use among out of school adolescent girls and young women aged 15-24: a case study of Majengo slums, Unpubl Work, Nairobi county, 2017.

[16] D. M. Morrison, S. A. Baker, and M. R. Gillmore, "Sexual risk behavior, knowledge, and condom use among adolescents in juvenile detention," Journal of Youth and Adolescence, vol. 23, no. 2, pp. 271-288, 1994.

[17] L. Kanda and R. Mash, "Reasons for inconsistent condom use by young adults in Mahalapye, Botswana," African Journal of Primary Health Care \& Family Medicine, vol. 10, no. 1, 2018.

[18] B. Njau, V. Mwakalo, and D. Mushi, "Correlates of use of condoms among sexually active youth in Southern Highlands, Tanzania," SAGE Open, vol. 3, no. 2, p. 215824401349140 , 2013.

[19] M. Masoda and I. Govender, "Knowledge and attitudes about and practices of condom use for reducing HIV infection among Goma University students in the Democratic Republic of Congo," Southern African Journal of Epidemiology and Infection, vol. 28, no. 1, pp. 61-68, 2015.

[20] F. Girmatsion, "Knowledge and misconception of young women toward sexual transmitted infection and condom use in Northern Ethiopia : cross sectional study," Journal of Public Health and Epidemiology, vol. 7, no. 4, pp. 138-144, 2015.

[21] M. A. Ochieng, R. Kakai, and K. Abok, "Knowledge, attitude and practice of condom use among secondary school students in Kisumu District, Nyanza Province," Asian Journal of Medical Sciences, vol. 3, no. 1, pp. 32-36, 2011.

[22] J. P. Espada, A. Morales, A. Guillén-Riquelme, R. Ballester, and M. Orgilés, "Predicting condom use in adolescents : a test of three socio-cognitive models using a structural equation modeling approach," BMC Public Health, vol. 16, no. 1, p. $35,2015$.

[23] A. Stulhofer, C. Graham, I. Bozicevic, K. Kufrin, and D. Ajdukovic, "HIV/AIDS-related knowledge, attitudes and sexual behaviors as predictors of condom use among young adults in Croatia," International Family Planning Perspectives, vol. 33, no. 2, pp. 58-65, 2007.

[24] Centeral Statistical Agency, "Ethiopia demographic and health survey: Preliminary Report," 2011.

[25] R. Potsonen, "How are attitudes towards condoms related to gender and sexual experiences among adolescents in Finland?," Health Promotion International, vol. 14, no. 3, pp. 211-220, 1999.

[26] W. Tipwareerom and L. Weglicki, "Parents' knowledge, attitudes, behaviors, and barriers to promoting condom use among their adolescent sons," Nursing \& Health Sciences, vol. 19, no. 2, pp. 212-219, 2017.

[27] Centeral Statistcal Agency, Ethiopian demographic and health survey : HIV prevalence report, 2016.

[28] A. S. Belay, Y. Worku, T. Addisu, and A. Alemneh, "Assessment of magnitude of risk sexual behavior among Mizan high school and preparatory school students, South West, Ethiopia, 2016: descriptive cross-sectional study," International Journal of Scientific Reports, vol. 4, no. 3, p. 68, 2018.
[29] N. Fetene and W. Mekonnen, "The prevalence of risky sexual behaviors among youth center reproductive health clinics users and non-users in Addis Ababa, Ethiopia: a comparative cross-sectional study," PLoS One, vol. 13, no. 6, article e0198657, 2018.

[30] A. G. Silassie and M. W. Giorgis, "Knowledge, attitude and practice of condom utilization among Axum preparatory school students," Journal of AIDS \& Clinical Research, vol. 7, no. $4,2016$.

[31] T. Yosef, A. Daniel, T. Nigussie, and Y. Girma, "Sexual behaviour among technical vocational and educational training (TVET) college students at Mizan-Aman Town, South West Ethiopia, 2018," Journal of AIDS \& Clinical Research, vol. 10, no. 10, pp. 1-4, 2019.

[32] M. Miskulin, I. Miskulin, J. Milas, A. Antolović-Požgain, S. Rudan, and J. Vukšic, "Prevalence and risk factors for herpes simplex virus type 2 infections in East Croatia," Collegium antropologicum, vol. 35, no. 1, pp. 9-14, 2011. 